\title{
$\begin{array}{ll}\text { Research Square } & \begin{array}{l}\text { Preprints are preliminary reports that have not undergone peer review. } \\ \text { They should not be considered conclusive, used to inform clinical practice, } \\ \text { or referenced by the media as validated information. }\end{array}\end{array}$
}

\section{Characteristics and outcomes of Stanford type A aortic dissection patients with post-operation severe hyperbilirubinemia: a retrospective cohort study}

Xiaolan Chen

Xijing Hospital

Ming Bai ( $D$ mingbai1983@126.com )

Xijing Hospital

Lijuan Zhao

Xijing Hospital

Yangping Li

Xijing Hospital

Yan Yu

Xijing Hospital

Wei Zhang

Xijing Hospital

Feng Ma

Xijing hospital

Shiren Sun ( $\square$ sunshiren@medmail.com.cn )

Xijing Hospital

Xiangmei Chen ( $\nabla$ xmchen301@126.com )

Xijing Hospital

\section{Research article}

Keywords: Stanford type A aortic dissection, hyperbilirubinemia, acute kidney injury, continuous renal replacement therapy

Posted Date: May 26th, 2020

DOI: https://doi.org/10.21203/rs.3.rs-30855/v1

License: (c) (i) This work is licensed under a Creative Commons Attribution 4.0 International License. Read Full License

Version of Record: A version of this preprint was published on July 28th, 2020. See the published version at https://doi.org/10.1186/s13019-020-01243-7. 


\section{Abstract \\ Background}

Hyperbilirubinemia is one of the common complications after cardiac surgery and is associated with increased mortality. However, to the best of our knowledge, the report on clinical significance of postoperative severe hyperbilirubinemia in Stanford type A aortic dissection (AAD) patients is limited.

\section{Methods}

Patients who underwent surgical treatment for AAD in our center between January 2015 and December 2018 were retrospectively screened. In-hospital mortality, long-term mortality, acute kidney injury (AKI), and the requirement of continuous renal replacement therapy (CRRT) were assessed as endpoints. Univariate and multivariate regression models were employed to identify the risk factors of these endpoints.

\section{Results}

271 (12.3\%) patients were included. Of the included patients, 222 (81.9\%) experienced postoperative AKI, and 50 (18.5\%) received CRRT. In-hospital mortality was 30.3\%. The 1-year, 2-year, and 3-year cumulative mortality were $32.9 \%$, 33.9\%, and $35.3 \%$, respectively. Multivariate Logistic regression analysis indicated that age $(P<0.033)$, AKI stage $3(P<0.001)$, the amount of blood transfusion after surgery $(P=0.019)$, mean arterial pressure (MAP) in the first postoperative day $(P=$ 0.012), the use of extracorporeal membrane oxygenation (ECMO) $(P=0.02)$, and the peak total bilirubin (TB) concentration $(P=0.023)$ were independent risk factors of in-hospital mortality. The optimal cut-off value of peak TB on predicting in-hospital mortality was $121.2 \mu \mathrm{mol} / \mathrm{l}$. Survival analysis showed significantly decreased survival for patients who developed severe, rather than mild, hyperbilirubinemia.

\section{Conclusions}

Post-operation severe hyperbilirubinemia is a common clinical presentation in AAD surgery patients. Post-operation severe hyperbilirubinemia AAD patients with older age, lower MAP, increased blood transfusion, stage 3 AKI, the use of ECMO, and the increased peak TB had higher risk of in-hospital mortality.

\section{Introduction}

Aortic dissection $(A D)$ is an acute life-threatening condition with a prevalence of about $3 / 100,000$ per year. The International Registry of $A D$ revealed that $67 \%$ of $A D$ patients presented with Stanford type $A$ aortic dissection (AAD), which was characteristic as the involvement of the ascending aorta. And, approximately $86 \%$ of $A A D$ patients required swift open cardiac surgery to avoid fatal complications such as aortic rupture and cardiac tamponade.[1-3] In spite of the improvement in medical management and surgical technique, AAD surgery was associated with early mortality as high as $20 \% .[4-8]$

Hyperbilirubinemia is a common severe complication after cardiac operation.[9] The reported incidence of post-operation hyperbilirubinemia varied widely $(10-57 \%)$ and related to the severity of cardiac diseases and the type of cardiac surgery. Although hyperbilirubinemia was reported to be associated with in-hospital mortality and mortality after discharge, the effects of hyperbilirubinemia on patient prognosis were heterogeneous.[10-14] For patients undergoing cardiac surgery with cardiopulmonary bypass (CPB), recent studies suggested that severe hyperbilirubinemia (5 times the normal upper 
limit) instead of mild bilirubin significantly increased patient mortality.[15] Additionally, the occurrence of acute kidney injury (AKI) and the acceptance of continuous renal replacement therapy (CRRT) after cardiac surgery were suggested to be associated with the decrease of patient survival proportion. As we know, the pathogenesis, disease severity classification, prognosis, and operation method are different between different cardiac diseases. The inclusion of all kinds of cardiac surgery in one study most likely would reduce the specificity and repeatability of the conclusions. Up to now, the reports on the characteristics and outcomes of AAD surgery patients who had post-operation severe hyperbilirubinemia are limited.

Therefore, the purpose of our present study is to describe the clinical characteristics and to investigate outcomes of AAD surgery patients who had post-operation severe hyperbilirubinemia. The results of our present study might be useful for decision makers regarding their treatment strategy and for patients and their families regarding the expected progression.

\section{Patients And Method}

\subsection{Study design and patients selection}

Our present study was retrospectively designed. Consecutive patients who underwent surgery for AD in our center between January 2015 and December 2018 were screened. AD was proven by enhanced computed tomography and defined as type A or type B according to the Stanford classification. Postoperative severe hyperbilirubinemia was defined as occurrence of a serum TB concentration of more than $85.5 \mu \mathrm{mol} / \mathrm{l}$ ( 5 times the normal upper limit) in any measurement during the hospital staying after AAD surgery. Patients were excluded if they had any of the following conditions: (1) serum TB concentration < $85.5 \mu \mathrm{mol} / \mathrm{l}$, (2) age < 18 years; (3) Stanford type B aortic dissection; (4) the occurrence of severe hyperbilirubinemia before surgery; (5) severe hyperbilirubinemia caused by the reoperation during hospitalization. The local Institutional Review Board of the hospital approved this retrospective study and waived the requirement of informed consent for the use of patients' medical data.

\subsection{Surgical procedure}

The use of surgical techniques has developed during the study period. However, the basic principles for repair of AAD have no change, including (1) prompt establishment of CPB, (2) resection of the primary entry site by open distal anastomosis under deep hypothermic circulatory arrest, (3) preservation of the aortic valve whenever possible, and (4) aortic arch replacement in patients with an entry site located in or extending into the aortic arch. Aortic root replacement with a composite prosthesis and reimplantation of the coronary arteries by the modified Bentall technique was performed in patients with conspicuous dilatation of the aortic root.

\subsection{Data collection}

Demographic data, comorbidities, and operation details were retrieved from our hospital's electronic medical record system. All the routine laboratory data was recorded before operation (the nearest to the time of surgery) and in the postoperation period. The severity of illness before and after surgery was assessed by using the acute physiology and chronic health evaluation II (APACHE II), sequential organ failure assessment (SOFA) score, and model for end-stage liver disease (MELD) score. Urine output was recorded every day after the surgery.

\subsection{Outcomes and definition}

Post-operation outcomes including the amount of blood transfusion, mechanical ventilation time, the use of extracorporeal membrane oxygenation (ECMO), intra-aortic balloon pump (IABP), AKI, the usage of CRRT, bilirubin adsorption (BA) or plasma exchange (PE), and vasoactive agent, the duration of hospitalization, ICU stay time, and inhospital mortality. For those patients who were alive on discharge, telephone survey was performed to obtain the patients long-term outcome. 
Kidney Disease Improving Global Outcomes (KDIGO) criteria[16] based on SCr or urine output was employed to diagnose and grade AKI. The latest SCr concentration before surgery was defined as preoperative SCr concentration. The decision to start CRRT was made at the discretion of the attending nephrologist. Main indications for starting CRRT were progressive AKI, fluid overload, hyperkalemia, and severe metabolic acidosis.[16]

\subsection{Statistical analysis}

Data were analyzed using SPSS version 22.0 software (SPSS, Inc, Chicago, IL, USA). Continuous variables are presented as mean \pm standard deviation. Categorical variables are presented as frequencies with percentages. To evaluate the differences between groups, the independent sample $t$-test was used for continuous variables, whereas the chi-square test or Fisher's exact test was used for categorical variables. Factors significantly associated with these endpoints in univariate analysis were included in the multivariate logistic regression analysis or Cox proportional hazard analysis to identify the independent risk factors. Accumulated survival proportion was estimated with the Kaplan-Meier method, and the between-group differences of survival proportion were assessed using the log-rank test. Area under the receiver operating characteristic curve (AUC-ROC) was calculated to assess peak TB concentration on the ability to detect inhospital mortality. Youden index was used for assessment of optimal cut-off values. For all analyses, all statistical tests were 2 -sided, and a $P$-value $<0.05$ was considered as statistically significant.

\section{Result}

\subsection{Patient characteristics}

Of the 2210 screened patients, 1931, 2, 3, and 3 were excluded because of TB concentration < 85.5umol/I, Stanford type B aortic dissection, preoperative TB $\geq 85.5 \mu \mathrm{mol} / \mathrm{l}$, and post-operation severe hyperbilirubinemia caused by reoperation during this hospitalization, respectively. Ultimately, 271 AAD surgery patients with post-operation severe hyperbilirubinemia were included in our present study (Fig. 1).

The baseline characteristics of the included patients were summarized in Table 1. There were 223 male and 48 female, and the mean age of the patients was $49.1 \pm 11.0$ years. AAD surgery involved the aortic valve in $83.8 \%$ patients, aortic arch in $86 \%$ patients, and coronary artery in $17 \%$ patients. Preoperative TB concentration was $25.0 \pm 15.0 \mu \mathrm{mol} / \mathrm{l}$. The mean onset time of severe hyperbilirubinemia was $2.8 \pm 1.3$ days after AAD surgery. The mean peak serum TB concentration was $150.9 \pm 93.0 \mu \mathrm{mol} / \mathrm{I}$ and the averaged time to peak TB concentration was $3.8 \pm 3.0$ days after AAD surgery. The change of TB concentration during the seven days after surgery was showed in Fig. 2 . The median follow-up time was 18.63 (0.5-55.9) months. And, 3 patients were lost to follow-up. The time of lost to follow-up was 16-, 95-, and 365-day after the surgery, respectively.

\subsection{Postoperative AKI}

Of the 271 included patients, 222 patients (82.1\%) had AKI after AAD surgery, of which 102 (40.2\%), 34 (12.5\%), and 84 (29.2\%) were stage 1, stage 2, and stage 3 AKI (Table 2), respectively. The results of univariate and multivariate logistic regression are presented in Table 3. In the univariate analysis, age, hypertension, preoperative SCr concentration, APACHE $\triangle$ score, and MELD score, operation time, and CPB time were associated with the occurrence of postoperative AKI. Multivariate analysis indicated that increased age (OR 1.056, 95\% Cl 1.026-1.088, $P<0.001)$, higher preoperative SCr concentration (OR 1.026, 95\% $\mathrm{Cl} 1.010-1.043, P=0.002)$, and prolonged $\mathrm{CPB}$ time (OR $1.007,95 \% \mathrm{Cl} 1.000-1.013, P=$ 0.042) were identified as independent risk factors of AKI in AAD surgery patients with post-operation severe hyperbilirubinemia.

\subsection{Postoperative CRRT}


Of the included patients, 50 (18.5\%) patients received CRRT after AAD surgery. Univariate analysis indicated that male, preoperative SCr concentration, APECHE $\triangle$ score, MELD score, and aortic cross-clamp (ACC) time were associated with the need for CRRT. In the multivariate logistic regression analysis, only preoperative $\mathrm{SCr}$ concentration $(\mathrm{OR} 1.011,95 \% \mathrm{Cl}$ 1.002-1016, $P=0.003$ ) was identified as an independent predictor of the acceptance of CRRT (Table 3).

\subsection{In-hospital mortality}

There were $82(30.3 \%)$ in-hospital deaths. Univariate analysis revealed that 20 pre-operation, intra-operation, and postoperation factors were associated with in-hospital mortality. After the adjustment of the important clinical parameters, independent risk factors of in-hospital mortality identified by multivariate logistic analysis included age $(\mathrm{OR} 1.005,95 \% \mathrm{Cl}$ 1.004-1.099, $P=0.033$ ), the amount of blood transfusion (OR 1.018,95\% Cl 1.003-1.033, $P=0.019$ ), stage $3 \mathrm{AKI}$ (OR $46.134,95 \% \mathrm{Cl} 5.436-391.525, P<0.001)$, the use of ECMO (OR 20.795, 95\% Cl 1.620-266.917, $P=0.02$ ), and the peak TB concentration (OR $1.017,95 \% \mathrm{Cl} 1.002-1.032, P=0.023)$. Postoperative MAP tended to be a protective factor (OR 0.955 , $95 \% \mathrm{Cl} 0.922-0.990, P=0.012$, Table 4, model 1).

ROC analysis (Fig. 3) identified that peak TB concentration was associated with increased mortality, and the optimal cutoff value identified by the Youden index was $121.2 \mu \mathrm{mol} / /$ (sensitivity: $72 \%$, specificity: $60 \%$ ). And, the multivariate analysis revealed that patients with peak TB concentration $\geq 121.2 \mu \mathrm{mol} / \mathrm{I}$ had a significantly higher risk of in-hospital mortality $(\mathrm{OR}=2.681,95 \% \mathrm{Cl} 1.119-6.425, P=0.027$, Table 4, model 2$)$, compared with the patients with peak TB concentration $<121.2 \mu \mathrm{mol} / \mathrm{l}$.

\subsection{Long-term mortality}

Of the 12 patients who died after discharge, 4 had non-AKI, 3 had stage 1 AKI, 3 had stage 2 AKI, and 2 had stage 3 AKI during their hospital stay, respectively. The accumulated 1-year, 2-year, and 3-year mortality proportions were 32.9\%, 33.9\%, and $35.3 \%$, respectively (Fig. 4A). The risk factors of long-term mortality were presented in Table 5. Univariate analysis revealed 20 factors, including the post-operation AKI, the acceptance of CRRT and ECMO, and the peak TB concentration $\geq 121.2 \mu \mathrm{mol} / \mathrm{I}$ (Fig. 4B-E), were significantly related to patient long-term mortality. Multivariate COX regression analysis revealed that stage $3 \mathrm{AKI}(\mathrm{HR} 12.604,95 \% \mathrm{Cl} 5.002-31.762, P<0.001)$ significantly increased long-term mortality, compared with patients without AKI. The use of ECMO (HR 12.167, 95\% Cl 4.588-32.264, $P<0.001)$ was identified as an independent predictor of long-term mortality as well. In contrast, postoperative MAP $(\mathrm{HR} 0.979,95 \% \mathrm{Cl} 0.962-0.995, P=$ 0.012) was identified as an independent protective factor of long-term mortality.

\section{Discussion}

It has been reported that severe hyperbilirubinemia was associated with increased mortality in patients underwent cardiac surgery. $[11,15,17]$ Up to now, limited information was available on the risk factors associated with in-hospital and longterm mortality in AAD patients with post-operation severe hyperbilirubinemia. Our presented study had several findings. Firstly, the occurrence of AKI, the requirement for CRRT, and the in-hospital mortality were higher than previous studies of patients undergoing AAD surgery without severe hyperbilirubinemia. Secondly, age, preoperative SCr concentration, and CPB time were independent risk factors for postoperative AKI, and preoperative SCr concentration was an independent risk factor for post-operation CRRT as well. Finally, the peak TB concentration, post-operation stage 3 AKI, the total amount of blood transfusion after AAD surgery, the use of ECMO, and low MAP after surgery were significantly associated with mortality.

\subsection{AAD patients with severe hyperbilirubinemia were associated with worse prognosis}


The analysis of our present cohort of AAD patients with post-operation severe hyperbilirubinemia showed an overall incidence of post-operation AKI of $81.9 \%$, a requirement for CRRT of $18.5 \%$, and the in-hospital mortality rate of $30.3 \%$. In previous studies of AAD patients underwent surgical treatment without post-operation severe hyperbilirubinemia, the reported AKI incidences were ranged from $40-78 \%,[5-7,18-23]$ the reported incidences of requirement for CRRT were ranged from $3 \%$ to $8 \%,[5,7]$ and the reported in-hospital mortalities were ranged from $15-26 \% .[4,5,7,19,24]$ The discrepancy most likely attributed to the fact that all of the included AAD patients in our study developed severe hyperbilirubinemia. The development of severe hyperbilirubinemia after AAD surgery related to the severity of the AAD and the severity of injury during AAD operation. In animal model, hyperbilirubinemia was proved to have pro-apoptotic effects and aggravate renal ischemia-reperfusion injury.[25] Additionally, high concentration of bilirubin could lead to inflammatory response and cell apoptosis of the brain,[26] which might be one of the potential mechanism of the high mortality of our present cohort.

\subsection{Risk factors of postoperative AKI and CRRT}

In our present cohort, older age, high preoperative SCr concentration, and pronged CPB time were identified as independent risk factors for AKI. Meanwhile, preoperative SCr concentration was also associated with the requirement of CRRT after AAD surgery. A recent meta-analysis of patients underwent AAD surgery[18] showed that older age was identified as an independent risk factor of $\mathrm{AKI}$ as well. Older age-mediated adverse renal structural and functional changes might contribute to the high development of postoperative AKI after AAD surgery in older patients. The aforementioned metaanalysis showed that preoperative SCr concentration did not correlate with postoperative AKI with significant heterogeneity $\left(\mathrm{I}^{2}=72.8 \%\right)$. In our opinion, pre-operation elevated $\mathrm{SCr}$ concentration might indicate structural kidney damage or hemodynamic derangements in AAD patients, which further aggravated the development of post-operation AKI and the requirement of CRRT. Longer CPB time can lead to more hemolysis, and a longer time on the circuit can lead to changes in perfusion to the viscera and to more inflammatory action. A CPB itself might also induce hypoperfusion of abdominal organs, hypoxia or an inflammatory reaction, which causes liver and kidney damage. Therefore, surgeons most likely could reduce the AKI risk of AAD patients by the improvement of their operation strategies and the reduction of CPB time.

\subsection{Risk factors of in-hospital and long-term mortality}

In previous studies, older age had been identified as an independent risk factor of mortality for patients with hyperbilirubinemia after cardiac surgery.[27] In our present study, older age was established a risk factor for in-hospital mortality for patients with hyperbilirubinemia after AAD surgery as well. Nevertheless, aging indicated diminished functional capacity of the liver and added to the cumulative burden in the case of developed severe hyperbilirubinemia. Additionally, different from the a recent study outlining the increased risk of mortality for patients with hyperbilirubinemia after cardiac surgery associated with time to peak bilirubin,[15] our study indicated that peak TB concentration was an independent driver of in-hospital mortality for patients with severe hyperbilirubinemia after AAD surgery. And, we found out that the optimal cut-off value of peak TB on predicting in-hospital mortality was $121.2 \mu \mathrm{mol} / \mathrm{l}$. This difference might be attributed to the existence of severe hyperbilirubinemia after AAD surgery and the limitation of small sample size. The high concentration of bilirubin leads to inflammatory response or cell apoptosis in the brain.[26] Cui et al.[28] showed that bilirubin induced lung edema and injury by inducing the apoptosis of alveolar epithelial cells. From the above, severe hyperbilirubinemia induces oxidative stress and apoptosis in many organs, which is associated with poor outcomes in patients with AAD surgery.

In a study for patients with jaundice after open heart surgery, Chu et al.[29] reported patients with more severe hyperbilirubinemia or delayed serum peak TB concentration might be significantly associated with more transfused blood and hypotension. Increased amount of blood transfusions contributed to hemolysis, and hypotension would reduce hepatic perfusion[30], which both caused an increased bilirubin load. This might be one of the potential mechanisms that the number of transfused blood units and lower MAP increased mortality in our present study. Previous studies suggested 
that mechanisms underlying the development of post-operation late peak TB concentration differed from those of the early peak bilirubin concentration. The immediate development of post-operation peak TB concentration and rapid decline thereafter reflected the transient damaging effects by CPB surgery, whereas late development of post-operation peak TB concentration was a consequence of hepatic dysfunction caused by persistent cardiac failure or sepsis. $[9,12]$ Therefore, attention should be paid to the monitoring of heart failure and optimizing hemodynamics after AAD surgery to prevent further deterioration. Furthermore, identifying and implementing effective risk reduction strategies is needed. Molecular adsorbent recirculation system, prometheus therapy, fractionated plasma separation and adsorption have shown promise in reducing bilirubin concentration,[27, 31] but further study in this area is needed.

AKI had been incorporated into a risk tool to predict early mortality for patients underwent AAD surgery.[18] Our results added to these findings and demonstrated stage 3 AKI markedly increased both in-hospital and long-term mortality. Additionally, our study also showed in-hospital and long-term mortality was independently predicted by the use of ECMO. Hemolysis is a common complication in ECMO support.[32] Pump head or oxygenator thrombosis and excessive pump speed (typically greater than $3000 \mathrm{rpm}$ ) which may destroy blood red cells,[33] which in turn is important factor in the development of hyperbilirubinemia. Therefore, more careful postoperative management is needed to improve prognosis.

\subsection{Study limitation}

Our present study was a retrospective clinical research from a single institution and had some limitations. First, $\mathrm{SCr}$ concentration on admission was regard as preoperative renal function. However, some patients might already have AKI on admission. As a result, the number of patients with AKI may be underestimated. Second, the number of major adverse events including the use of ECMO, plasma exchange and bilirubin adsorption was small, which will be likely to reduce the statistical power for risk factor analysis. Finally, the renal prognosis was not regular followed up after the hospital discharge, which is important for the evaluation of the renal outcome. Therefore, further prospective multicenter studies with larger samples are needed to obtain stronger evidences.

\section{Conclusion}

Post-operation severe hyperbilirubinemia is a common clinical presentation in AAD surgery patients. Post-operation severe hyperbilirubinemia AAD patients with older age, lower MAP, increased blood transfusion, stage $3 \mathrm{AKI}$, the use of ECMO, and the increased peak TB had higher risk of in-hospital mortality. These patients most likely need more intensive monitoring.

\section{Abbreviations}




\begin{tabular}{ll} 
AAD & Stanford type A aortic dissection \\
\hline AKI & Acute kidney injury \\
\hline ACC & Aortic cross clamp \\
\hline APECHEII & Acute physiology and chronic health evaluation II \\
\hline BA & Bilirubin adsorption \\
\hline CPB & Cardiopulmonary bypass \\
\hline CRRT & Continuous renal replacement therapy \\
\hline ECMO & Extracorporeal membrane oxygenation \\
\hline IABP & Intra-aortic balloon pump \\
\hline ICU & Intensive care unit; \\
\hline MAP & Mean arterial pressure \\
\hline MELD & Model for end-stage liver disease \\
\hline PE & Plasma exchange \\
\hline SCr & Serum creatinine \\
\hline SOFA & Sequential organ failure assessment \\
\hline TB & Total bilirubin \\
\hline
\end{tabular}

\section{Declarations}

\section{Acknowledgments}

Not applicable.

\section{Funding Source}

This work was supported by the National Natural Science Foundation of China (81700584) and Discipline Promotion Project of Xijing Hospital (XJZT18ML16).

\section{Availability of data and materials}

The datasets used or analyzed during the current study are available from the corresponding author on reasonable request.

\section{Contributions}

Chen, Bai, Zhao, and Sun analyzed and interpreted the data. Li, Yu, Zhang, Ma and Chen performed the statistical analyses. All authors contributed to the study design and interpretation of the study results. All authors read and approved the final manuscript.

\section{Corresponding author}

Correspondence to Ming Bai, Shiren Sun1, Xiangmei Chen. 


\section{Ethics declarations}

\section{Ethics approval and consent to participate}

The local Institutional Review Board of the hospital approved this retrospective study and waived the requirement of informed consent for the use of patients' medical data, and all experimental methods were performed in accordance with the relevant guidelines and regulations.

\section{Consent for publication}

Not applicable.

\section{Competing interests}

The authors have declared that no interest.

\section{Publisher's Note}

Springer Nature remains neutral with regard to jurisdictional claims in published maps and institutional affiliations.

\section{References}

1. Nienaber CA, Clough RE. Management of acute aortic dissection. The Lancet. 2015;385:800-11.

2. Nienaber CA, Clough RE, Sakalihasan N, et al. Aortic dissection. Nat Rev Dis Primers. 2016;2:16053.

3. Evangelista A, Isselbacher EM, Bossone E, et al. Insights From the International Registry of Acute Aortic Dissection: A 20-Year Experience of Collaborative Clinical Research. Circulation. 2018;137:1846-60.

4. Tsai HS, Tsai FC, Chen YC, et al. Impact of acute kidney injury on one-year survival after surgery for aortic dissection. Ann Thorac Surg. 2012;94:1407-12.

5. Sasabuchi Y, Kimura N, Shiotsuka J, et al. Long-Term Survival in Patients With Acute Kidney Injury After Acute Type A Aortic Dissection Repair. Ann Thorac Surg. 2016;102:2003-9.

6. Roh GU, Lee JW, Nam SB, et al. Incidence and risk factors of acute kidney injury after thoracic aortic surgery for acute dissection. Ann Thorac Surg. 2012;94:766-71.

7. Ko T, Higashitani M, Sato A, et al. Impact of Acute Kidney Injury on Early to Long-Term Outcomes in Patients Who Underwent Surgery for Type A Acute Aortic Dissection. Am J Cardiol. 2015;116:463-8.

8. Schoenrath F, Laber R, Maralushaj M, et al. Survival, Neurologic Injury, and Kidney Function after Surgery for Acute Type A Aortic Dissection. Thorac Cardiovasc Surg. 2016;64:100-7.

9. Wang MJ, Chao A, Huang $\mathrm{CH}$, et al. Hyperbilirubinemia after cardiac operation. Incidence, risk factors, and clinical significance. J Thorac Cardiovasc Surg. 1994;108:429-36.

10. Collins JD, Bassendine MF, Ferner R, et al. Incidence and prognostic importance of jaundice after cardiopulmonary bypass surgery. Lancet. 1983;1:1119-23.

11. Sharma P, Ananthanarayanan C, Vaidhya N, et al. Hyperbilirubinemia after cardiac surgery: An observational study. Asian Cardiovasc Thorac Ann. 2015;23:1039-43.

12. Hsu RB, Lin FY, Chen RJ, et al. Incidence, risk factors, and prognosis of postoperative hyperbilirubinemia after heart transplantation. Eur J Cardiothorac Surg. 2007;32:917-22.

13. Lockey E, McIntyre N, Ross DN, et al. Early jaundice after open-heart surgery. Thorax. 1967;22:165-9.

14. Nishi H, Sakaguchi T, Miyagawa S, et al. Frequency, risk factors and prognosis of postoperative hyperbilirubinemia after heart valve surgery. Cardiology. 2012;122:12-9. 
15. Farag M, Veres G, Szabo G, et al. Hyperbilirubinaemia after cardiac surgery: the point of no return. ESC heart failure. 2019;6:694-700.

16. Group KDIGOKAKIW. KDIGO Clinical Practice Guideline for Acute Kidney Injury. Kidney Int Suppl. 2012:1-138.

17. Michalopoulos A, Alivizatos P, Geroulanos S. Hepatic dysfunction following cardiac surgery: determinants and consequences. Hepato-gastroenterology. 1997;44:779-83.

18. Wang J, Yu W, Zhai G, et al. Independent risk factors for postoperative AKI and the impact of the AKI on 30-day postoperative outcomes in patients with type $A$ acute aortic dissection: an updated meta-analysis and metaregression. Journal of thoracic disease. 2018;10:2590-8.

19. Zhao H, Pan X, Gong Z, et al. Risk factors for acute kidney injury in overweight patients with acute type A aortic dissection: a retrospective study. Journal of thoracic disease. 2015;7:1385-90.

20. Zhou H, Wang G, Yang L, et al. Acute Kidney Injury After Total Arch Replacement Combined With Frozen Elephant Trunk Implantation: Incidence, Risk Factors, and Outcome. J Cardiothorac Vasc Anesth. 2018;32:2210-7.

21. Qiu Z, Chen L, Cao H, et al. Analysis of risk factors for acute kidney injury after ascending aortic replacement combined with open placement of triple-branched stent graft in type A aortic dissection: a new technique versus the traditional method in a single Chinese center. Medical science monitor: international medical journal of experimental clinical research. 2015;21:674-80.

22. Luo HY, Hu KJ, Liu ZY, et al. [Analysis of the risk factors of postoperative renal failure of type A aortic dissection]. Zhonghua wai ke za zhi [Chinese journal of surgery]. 2008;46:1070-2.

23. Xu S, Liu J, Li L, et al. Cardiopulmonary bypass time is an independent risk factor for acute kidney injury in emergent thoracic aortic surgery: a retrospective cohort study. J Cardiothorac Surg. 2019;14:90.

24. Anil Z. Apaydin SB, Posacioglu H. Fatih Islamoglu,Tanzer Calkavur, Tahir Yagdi, Mustafa Ozbaran and, Yuksel M. Perioperative Risk Factors for Mortality in Patients With Acute Type A Aortic Dissection. Ann Thorac Surg. 2002;74.

25. Yuan L, Liao PP, Song HC, et al. Hyperbilirubinemia Induces Pro-Apoptotic Effects and Aggravates Renal Ischemia Reperfusion Injury. Nephron. 2019;142:40-50.

26. Barateiro A, Domingues HS, Fernandes A, et al. Rat cerebellar slice cultures exposed to bilirubin evidence reactive gliosis, excitotoxicity and impaired myelinogenesis that is prevented by AMPA and TNF-alpha inhibitors. Mol Neurobiol. 2014;49:424-39.

27. Komardina $\mathrm{E}$, Yaroustovsky M, Abramyan M, et al. Prometheus therapy for the treatment of acute liver failure in patients after cardiac surgery. Kardiochir Torakochirurgia Pol. 2017;14:230-5.

28. Cui J, Zhao H, Yi B, et al. Dexmedetomidine Attenuates Bilirubin-Induced Lung Alveolar Epithelial Cell Death In Vitro and In Vivo. Crit Care Med. 2015;43:e356-68.

29. Chu CM, Chang CH, Liaw YF, et al. Jaundice after open heart surgery: a prospective study. Thorax. 1984;39:52-6.

30. Mundth ED, Keller AR, Austen WG. Progressive hepatic and renal failure associated with low cardiac output following open-heart surgery. J Thorac Cardiovasc Surg. 1967;53:275-84.

31. Mitzner SR, Stange J, Klammt S, et al. Improvement of hepatorenal syndrome with extracorporeal albumin dialysis MARS: results of a prospective, randomized, controlled clinical trial. Liver transplantation: official publication of the American Association for the Study of Liver Diseases and the International Liver. Transplantation Society. 2000;6:277-86.

32. Pan KC, McKenzie DP, Pellegrino V, et al. The meaning of a high plasma free haemoglobin: retrospective review of the prevalence of haemolysis and circuit thrombosis in an adult ECMO centre over 5 years. Perfusion. 2016;31:223-31.

33. Toomasian JM, Bartlett RH. Hemolysis and ECMO pumps in the 21st Century. Perfusion. 2011;26:5-6.

\section{Tables}

Page $10 / 18$ 
Table 1. Baseline characteristics of the included patients

\begin{tabular}{|c|c|}
\hline Variables & Value \\
\hline \multicolumn{2}{|l|}{ Preoperative } \\
\hline Age, mean \pm SD (years ) & $49.1 \pm 11.0$ \\
\hline Male, n (\%) & $223(82.3 \%)$ \\
\hline \multicolumn{2}{|l|}{ Co-morbidity } \\
\hline Hypertension, n (\%) & $158(58.3 \%)$ \\
\hline Diabetes, n (\%) & $3(1.1 \%)$ \\
\hline Cerebrovascular disease, $\mathrm{n}(\%)$ & $16(5.9 \%)$ \\
\hline Previous cardiac surgery, n (\%) & $8(2.9 \%)$ \\
\hline APECHEII score, mean \pm SD & $9.2 \pm 3.2$ \\
\hline MELD score, mean \pm SD & $9.2 \pm 4.1$ \\
\hline SOFA score, mean \pm SD & $2.1 \pm 1.5$ \\
\hline $\mathrm{MAP}$, mean $\pm \mathrm{SD}(\mathrm{mm} / \mathrm{Hg})$ & $90.5 \pm 12.9$ \\
\hline $\mathrm{TB}$, mean $\pm \mathrm{SD}(\mu \mathrm{mol} / \mathrm{l})$ & $25.0 \pm 15.0$ \\
\hline $\mathrm{CB}$, mean $\pm \mathrm{SD}(\mu \mathrm{mol} / \mathrm{l})$ & $7.8 \pm 8.1$ \\
\hline $\mathrm{WBC}$, mean $\pm \mathrm{SD}\left(10^{9} / \mathrm{l}\right)$ & $11.7 \pm 5.0$ \\
\hline $\mathrm{Hb}$, mean $\pm \mathrm{SD}(\mathrm{g} / \mathrm{l})$ & $136.1 \pm 19.9$ \\
\hline $\mathrm{PLT}$, mean $\pm \mathrm{SD}\left(10^{9} / \mathrm{l}\right)$ & $157.2 \pm 68.5$ \\
\hline $\mathrm{SCr}$, mean $\pm \mathrm{SD}(\mu \mathrm{mol} / \mathrm{l})$ & $111.1 \pm 38.3$ \\
\hline $\mathrm{PT}$, mean $\pm \mathrm{SD}(\mathrm{s})$ & $12.0 \pm 2.2$ \\
\hline \multicolumn{2}{|l|}{ Intraoperative } \\
\hline \multicolumn{2}{|l|}{ Type of operation } \\
\hline Aortic valve, n (\%) & $227(83.8 \%)$ \\
\hline Aortic arch, n (\%) & $233(86 \%)$ \\
\hline Coronary artery, n (\%) & $46(17 \%)$ \\
\hline Operation duration, mean \pm SD $(\mathrm{h})$ & $6.8 \pm 1.6$ \\
\hline CPB time, mean $\pm \mathrm{SD}(\min )$ & $226.5 \pm 60.9$ \\
\hline ACC time, mean $\pm \mathrm{SD}(\min )$ & $102.2 \pm 28.0$ \\
\hline The amount of blood transfusion (U) & $18.8 \pm 10.6$ \\
\hline \multicolumn{2}{|l|}{ Postoperative } \\
\hline APECHE II score & $16.9 \pm 2.5$ \\
\hline SOFA score & $12.1 \pm 2.6$ \\
\hline Meld score & $18.6 \pm 4.4$ \\
\hline $\mathrm{AST}$, mean $\pm \mathrm{SD}(\mathrm{U} / \mathrm{L})$ & $347.6 \pm 1387.2$ \\
\hline $\mathrm{ALT}$, mean $\pm \mathrm{SD}(\mathrm{U} / \mathrm{L})$ & $164.4 \pm 526.6$ \\
\hline $\mathrm{TB}$, mean $\pm \mathrm{SD}(\mu \mathrm{mol} / \mathrm{l})$ & $189.1 \pm 74.6$ \\
\hline $\mathrm{CB}$, mean $\pm \mathrm{SD}(\mu \mathrm{mol} / \mathrm{l})$ & $110.7 \pm 37.9$ \\
\hline $\mathrm{WBC}$, mean $\pm \mathrm{SD}\left(10^{9} / \mathrm{l}\right)$ & $12.9 \pm 4.8$ \\
\hline $\mathrm{Hb}$, mean $\pm \mathrm{SD}(\mathrm{g} / \mathrm{l})$ & $112.9 \pm 16.6$ \\
\hline $\mathrm{PLT}$, mean $\pm \mathrm{SD}\left(10^{9} / \mathrm{l}\right)$ & $99.8 \pm 49.5$ \\
\hline
\end{tabular}


ACC, Aortic cross clamp; APECHEII, acute physiology and chronic health evaluation II; CB, conjugated bilirubin; CPB, cardiopulmonary bypass; Hb, hemoglobin; MAP, mean arterial pressure; MELD, model for end-stage liver disease; min, minute; PLT, platelet; PT, prothrombin time; SCr, serum creatinine; SD, standard deviation; SOFA, sequential organ failure assessment; TB, total bilirubin; WBC, white blood cell.

Table 2. The major outcomes of the included patients

\begin{tabular}{|c|c|}
\hline Variables & Value \\
\hline In-hospital mortality, n (\%) & $82(30.3 \%)$ \\
\hline Reoperation, n (\%) & $17(6.3 \%)$ \\
\hline $\mathrm{AKI}, \mathrm{n}(\%)$ & $222(81.9 \%)$ \\
\hline \multicolumn{2}{|l|}{ Stage of AKI } \\
\hline Stage $1, \mathrm{n}(\%)$ & $102(40.2 \%)$ \\
\hline Stage $2, \mathrm{n}(\%)$ & $34(12.5 \%)$ \\
\hline Stage $3, \mathrm{n}(\%)$ & $84(29.2 \%)$ \\
\hline Use of CRRT, n (\%) & $50(18.5 \%)$ \\
\hline Use of $\mathrm{PE} / \mathrm{BA}, \mathrm{n}(\%)$ & $11(14.1 \%)$ \\
\hline Use of IABP, $\mathrm{n}(\%)$ & $1(0.4 \%)$ \\
\hline Use of ECMO, n (\%) & $7(2.6 \%)$ \\
\hline Use of vasoactive agent, $\mathrm{n}(\%)$ & $173(63.8 \%)$ \\
\hline Mechanical ventilation time, mean $\pm \mathrm{SD}$ (days) & $3.3 \pm 5.7$ \\
\hline The amount of blood transfusion, mean \pm SD (U) & $34.8 \pm 43.3$ \\
\hline In hospital time, mean $\pm \mathrm{SD}$ (days) & $19.8 \pm 10.7$ \\
\hline ICU stay time, mean \pm SD (days) & $6.6 \pm 6.3$ \\
\hline Onset of severe hyperbilirubinemia, mean \pm SD (days) & $2.8 \pm 1.3$ \\
\hline
\end{tabular}

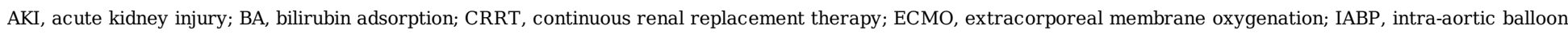
pump; ICU, intensive care unit; PE, plasma exchange. 


\begin{tabular}{|c|c|c|c|c|}
\hline \multirow[t]{2}{*}{ Characteristic } & \multicolumn{2}{|c|}{ Univariate logistic regression } & \multicolumn{2}{|c|}{ Multivariate logistic regression } \\
\hline & OR $(95 \% \mathrm{CI} \square$ & $P$ value & OR $(95 \% \mathrm{CI} \square$ & $P$ value \\
\hline \multicolumn{5}{|l|}{ Postoperative AKI } \\
\hline Age & $1.061(1.032-1.092)$ & $<0.001$ & $1.056(1.026$ - 1.088) & $<0.001$ \\
\hline Hypertension (yes/no) & $2.766(1.469-5.208)$ & 0.002 & & \\
\hline \multicolumn{5}{|l|}{ Preoperative } \\
\hline $\mathrm{SCr}$ & $1.030(1.014-1.047)$ & $<0.001$ & $1.026(1.010-1.043)$ & 0.002 \\
\hline APECHE II score & 1.399 (1.213 - 1.615) & $<0.001$ & & \\
\hline MELD score & $1.130(1.035-1.233)$ & 0.007 & & \\
\hline Operation duration & $1.346(1.089-1.633)$ & 0.006 & & \\
\hline CPB time & $1.008(1.001-1.014)$ & 0.015 & $1.007(1.000-1.013)$ & 0.042 \\
\hline \multicolumn{5}{|l|}{ Postoperative CRRT } \\
\hline Male (yes/no) & $4.006(1.192-13.462)$ & 0.025 & & \\
\hline \multicolumn{5}{|l|}{ Preoperative } \\
\hline $\mathrm{SCr}$ & $1.011(1.003-1.018)$ & 0.004 & $1.009(1.002-1016)$ & 0.017 \\
\hline APECHE II score & $1.333(1.033-1.244)$ & 0.008 & & \\
\hline MELD score & $1.083(1.007-1.164)$ & 0.032 & & \\
\hline ACC time & $1.011(1.000-1.022)$ & 0.049 & & \\
\hline
\end{tabular}

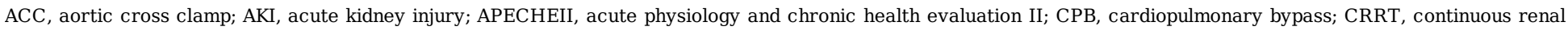
replacement therapy; MELD, model for end-stage liver disease; SCr, serum creatinine

Table 4. Logistic regression analysis for in-hospital mortality 


\begin{tabular}{|c|c|c|c|c|c|c|}
\hline \multirow{2}{*}{$\begin{array}{l}\text { In-hospital mortality } \\
\text { Characteristic }\end{array}$} & \multicolumn{2}{|c|}{ Univariate logistic regression } & \multicolumn{2}{|c|}{$\begin{array}{l}\text { Multivariate logistic regression } \\
\text { (model 1) }\end{array}$} & \multicolumn{2}{|c|}{$\begin{array}{l}\text { Multivariate logistic regression } \\
\text { (model 2) }\end{array}$} \\
\hline & OR $(95 \% \mathrm{CI} \square$ & $P$ value & OR $(95 \% \mathrm{CI} \square$ & $P$ value & OR $(95 \% \mathrm{CI} \square$ & Pvalue \\
\hline Age (yes/no) & $1.035(1.009-1.062 \square$ & 0.008 & $1.005(1.004-1.099)$ & 0.033 & $1.046(1.002-1.093)$ & 0.040 \\
\hline Male (yes/no) & $2.483(1.106-5.575)$ & 0.027 & & & & \\
\hline \multicolumn{7}{|l|}{ Preoperative } \\
\hline $\mathrm{SCr}$ & $1.009(1.002-1.016)$ & 0.008 & & & & \\
\hline APECHE II score & $1.178(1.082-1.282)$ & $<0.001$ & & & & \\
\hline \multicolumn{7}{|l|}{ Intraoperative } \\
\hline CPB time & $1.007(1.003-1.011)$ & 0.002 & & & & \\
\hline ACC time & $1.012(1.002-1.021)$ & 0.014 & & & & \\
\hline \multicolumn{7}{|l|}{ Postoperative } \\
\hline MAP & $0.948(0.926-0.971)$ & $<0.001$ & $0.955(0.922-0.990)$ & 0.012 & $0.963(0.930-0.977)$ & 0.031 \\
\hline The total amount of blood transfusion & $1.046(1.032-1.060)$ & $<0.001$ & $1.018(1.003-1.033)$ & 0.019 & $1.020(1.005-1.034)$ & 0.007 \\
\hline Mechanical ventilation time & $1.533(1.341-1.798)$ & $<0.001$ & & & & \\
\hline AKI (yes/no) & $\begin{array}{l}28.350(3.842- \\
209.203)\end{array}$ & 0.001 & & & & \\
\hline Stage of AKI & & $<0.001$ & & $<0.001$ & & $<0.001$ \\
\hline Stage 1 & $\begin{array}{l}5.859(0.735- \\
46.720)\end{array}$ & 0.095 & $2.424(0.267-21.990)$ & 0.431 & $2.218(0.253-19.426)$ & 0.472 \\
\hline Stage 2 & $\begin{array}{l}10.138(1.162- \\
88.457)\end{array}$ & 0.036 & $4.560(0.478-43.545)$ & 0.187 & $\begin{array}{l}3.698(0.385- \\
35.548)\end{array}$ & 0.257 \\
\hline Stage 3 & $\begin{array}{l}165.053(21.354- \\
1275.729)\end{array}$ & $<0.001$ & $\begin{array}{l}46.134(5.436- \\
391.525)\end{array}$ & $<0.001$ & $\begin{array}{l}46.318(5.666- \\
378.663)\end{array}$ & 46.318 \\
\hline Use of CRRT (yes/no) & $\begin{array}{l}23.756(10.359- \\
54.481)\end{array}$ & 0.001 & & & & \\
\hline Use of ECMO (yes/no) & $\begin{array}{l}14.842(1.757- \\
125.357)\end{array}$ & 0.013 & $\begin{array}{l}20.795(1.620- \\
266.917)\end{array}$ & 0.02 & $\begin{array}{l}10.130(0.900- \\
113.958)\end{array}$ & 0.061 \\
\hline Peak TB concentration & $1.009(1.005-1.012)$ & $<0.001$ & $1.017(1.002-1.032)$ & 0.023 & & \\
\hline Peak TB $\geq 121 \mu \mathrm{mol} / \mathrm{l}$, (yes/no) & $3.899(2.220-6.847)$ & $<0.001$ & & & $2.681(1.119-6.425)$ & 0.027 \\
\hline Peak TB > 171 $\mu \mathrm{mol} / \mathrm{l}$, (yes/no) & $3.785(2.045-7.005)$ & $<0.001$ & & & & \\
\hline Time to peak TB concentration & $1.441(1.277-1.626)$ & $<0.001$ & & & & \\
\hline ICU stay time & $1.268(1.172-1.371)$ & $<0.001$ & & & & \\
\hline
\end{tabular}

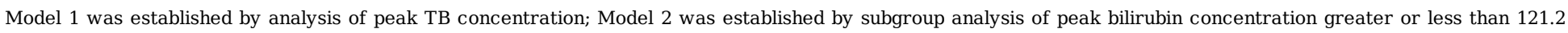
$\mu \mathrm{mol} / \mathrm{l}$

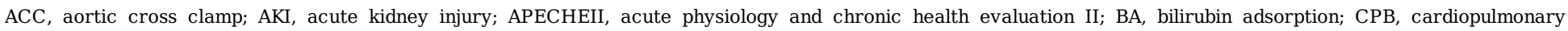

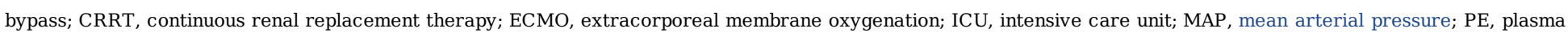
exchange; SCr, serum creatinine; TB, total bilirubin

\section{Figures}




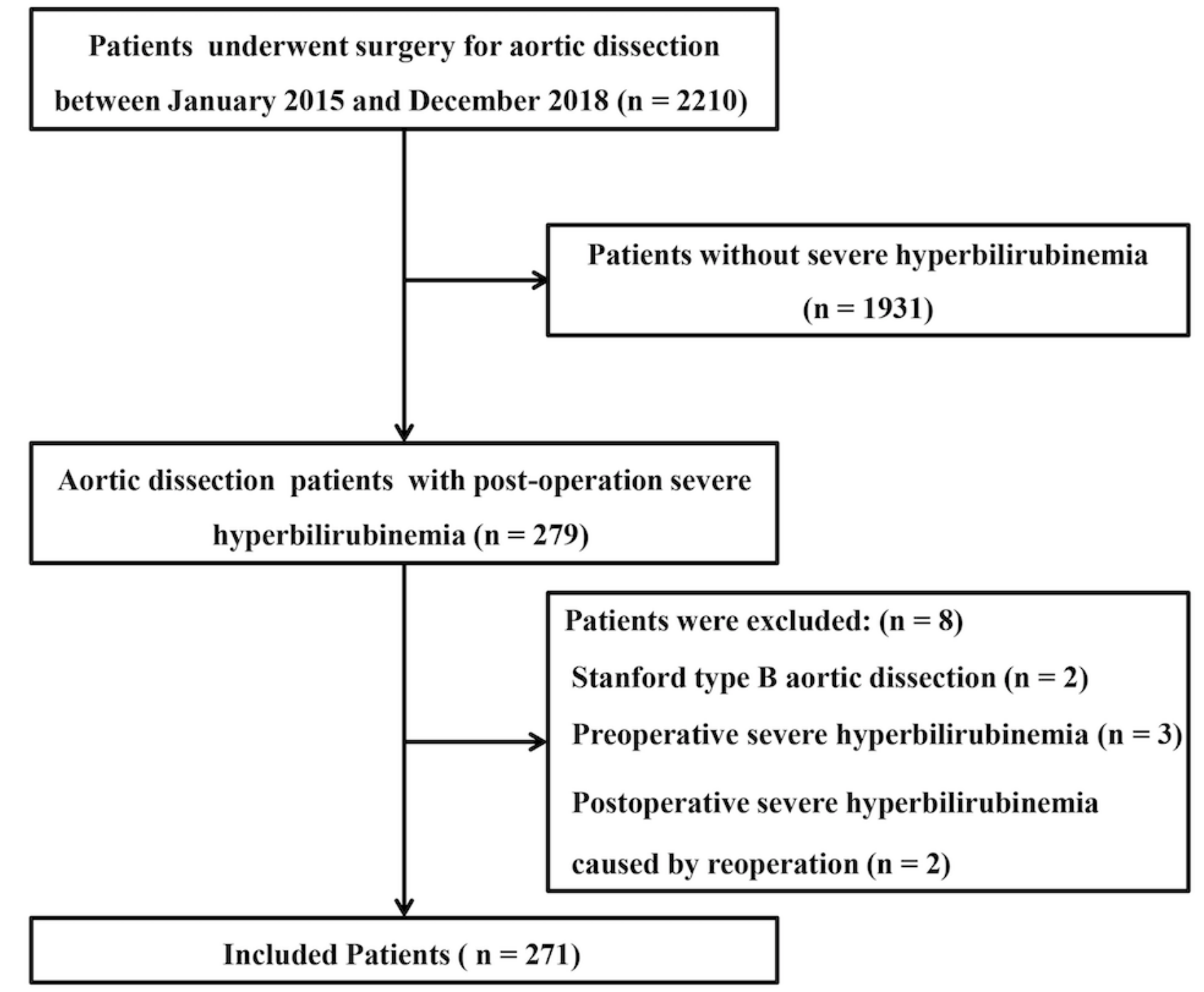

Figure 1

Patient inclusion flow chart 


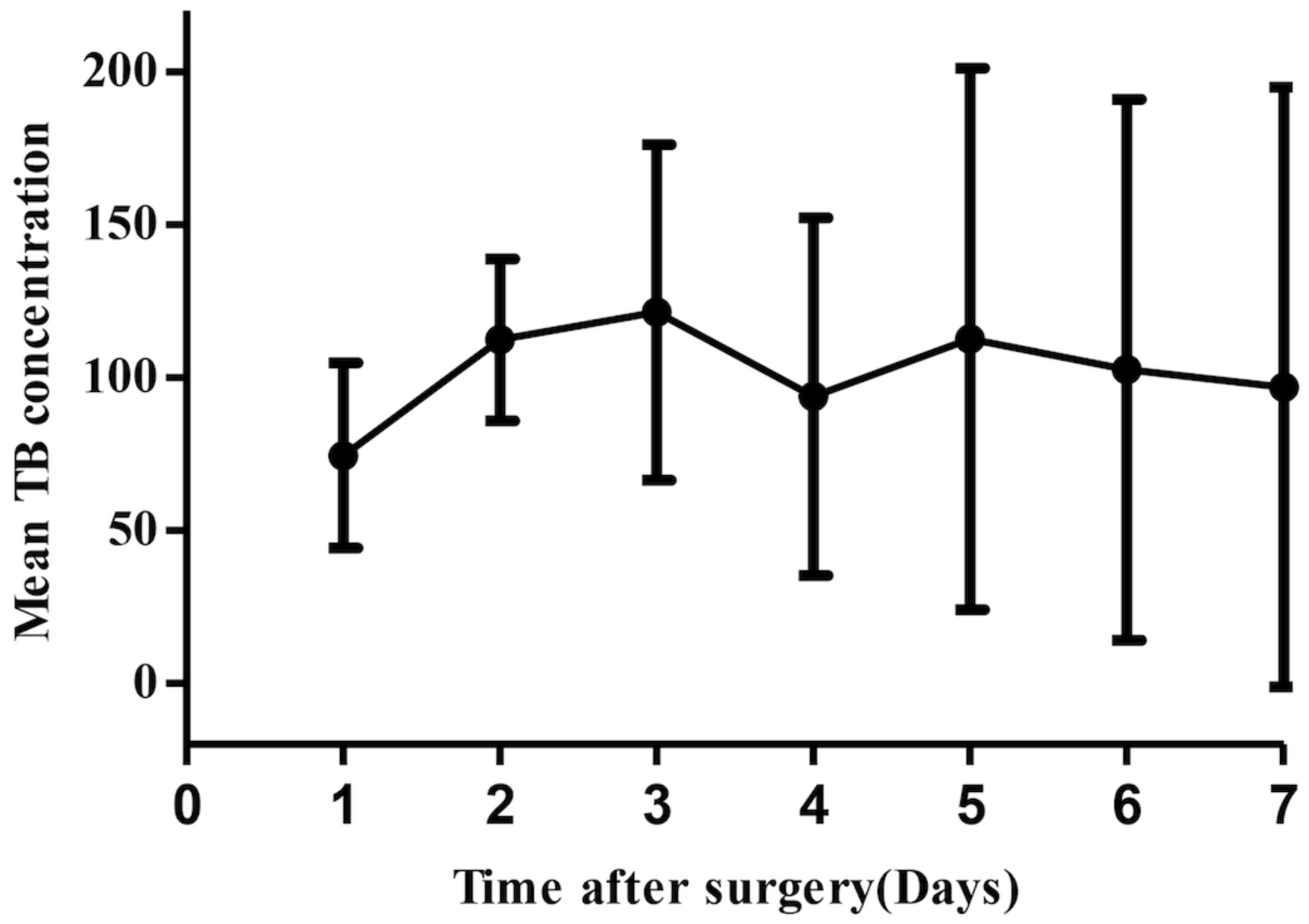

Figure 2

The averaged serum total bilirubin concentration during the postoperative seven days 


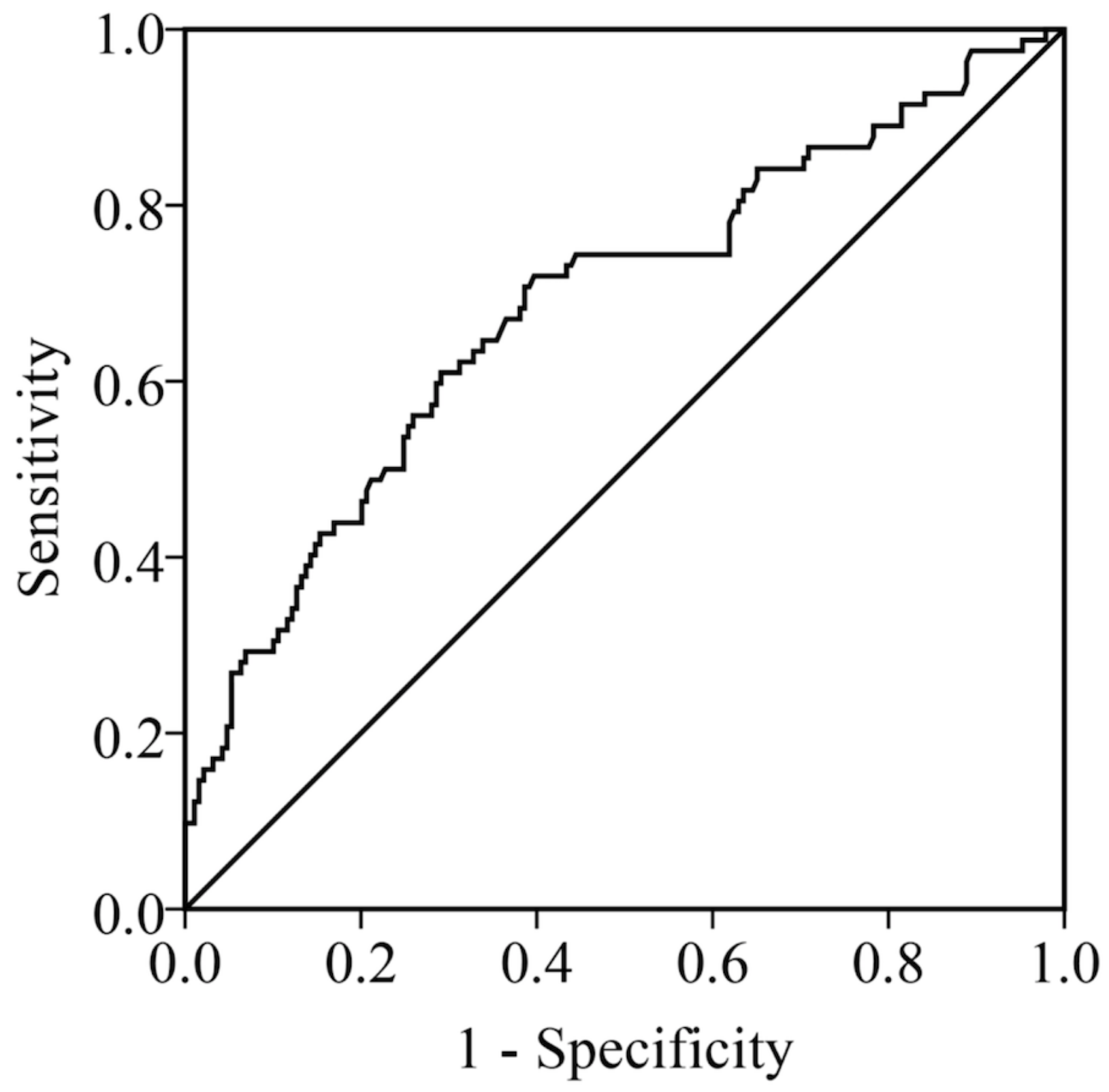

Figure 3

Receiver operator curve (ROC) of peak TB concentration predicting in-hospital mortality (area under the curve: $0.68,95 \%$ Cl: 0.614 - 0.758) 


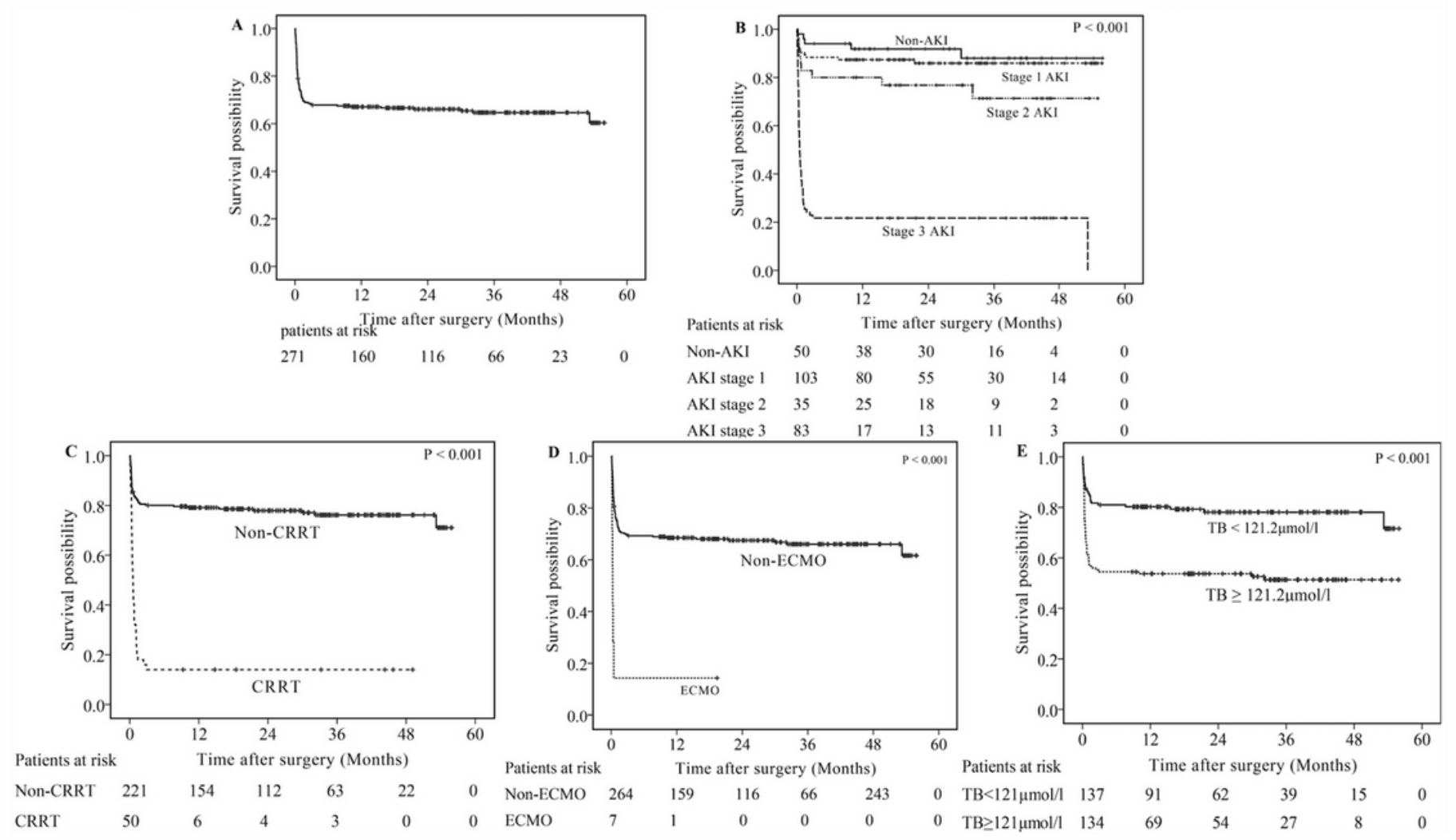

Figure 4

Long-term survival results of (A) all patients, (B) patients without AKI and those with stage 1, 2, or 3 AKI, (C) patients without the use of CRRT and those with CRRT, (D) patients without the use of ECMO and those with ECMO, (E) patients with post-operation peak TB $\geq 121.2 \mu \mathrm{mol} / \mathrm{I}$ and those with post-operation peak TB $<121.2 \mu \mathrm{mol} / \mathrm{l}$. 